\title{
Role of Private Garage Mechanics in Influencing Car Purchase
}

\author{
S S Krishna Kumar ${ }^{1} \&$ Bhanu Sree Reddy ${ }^{2}$ \\ ${ }^{1}$ Research Scholar, VIT Business School, VIT University, Vellore, India \\ ${ }^{2}$ VIT Business School, VIT University, Vellore, India \\ Correspondence: S S Krishna Kumar, Research Scholar, VIT Business School, VIT University, Vellore 632104, \\ India. E-mail: krishnakumartvs@yahoo.com
}

Received: April 7, 2013 Accepted: May 31, 2013 Online Published: August 1, 2013

doi:10.5539/ass.v9n10p169 URL: http://dx.doi.org/10.5539/ass.v9n10p169

\begin{abstract}
A private garage mechanic is the first level contact point for any car owner, by virtue of his proximity and accessibility in the society. However, the potential car owners (intending buyers of cars) look at these mechanics with mixed opinions. While a set of potential car owners view them as an excellent source of information for taking the purchase decision, there is another set of potential car owners, who don't trust these mechanics, suspecting them of having vested interest. The car manufacturers too view them with suspicion. However, these mechanics are seen as 'necessary evils' due to their ability to spread negative word of mouth and hence, it becomes necessary to nurture them.
\end{abstract}

Keywords: private garage mechanics, potential customers, recommendation, technical knowledge, credible

\section{Introduction}

The background of the private garage mechanics is very diverse and complex. "The garage is a place with traditional garage doors. The garages allow cars to be pulled into the working area, where jacks, lifts, and an assortment of other tools for car repair await. The car garage found at the car shop is often filled with oil cans, car parts, and cars in disrepair" (http://www.wisegeek.com/what-is-a-car-garage.htm). These garages are distinctly different from the authorised service centres of manufacturers. They lack the sophistication and technological prowess of a manufacturer authorised service centre. They also lack the systems and processes, adopted by the authorised service centres.

Only about $20 \%$ of the private garage mechanics have completed their school education (Source: Automobile Mechanics Association, Hosur, India). They come from financially poor background and were forced to work at a very early age. Typically, they start their career as assistants or helpers in an existing garage. They don't choose this profession by choice. They come here due to the employment opportunity available in these private garages. They do all sundry jobs like cleaning and washing of vehicles, before the more experienced mechanics take over technical jobs. They also act as errand boys to the more senior mechanics. Over time, they learn more by watching the senior mechanics and also by practicing on hand. More they practice, more they understand the complex nature of an automobile, leading to gaining expertise. The key is self-initiative and those with self-initiative learn the ropes very fast. Once they gain expertise, they try entrepreneurship and start their own garage. Normally, it takes about 10 years for someone to start his own garage, after he starts the work.

The entry cost in to this profession is not very high. "The industry is highly competitive with suppliers having a great deal of power in setting and negotiating the prices of their products and services to repair shops. In addition, because the customers see the service as undifferentiated and a 'commodity' with little value separation between competitors, buyer power is also very high. Finally, the barriers to entry are moderately low and the large numbers of competitors in this field including substitutes (such as do-it-yourself work) mean that the pricing for such services are very competitive. The only way to have an advantage in this industry is a low cost leadership principle applied aggressively or to create higher switching costs through the building of strong business to customer ties" (http://www.bplans.com/auto_repair_shop_business_plan/services_fc.php). This emphasises the importance of creating differentiation, from areas outside the conventional area of repairs.. A suitable rented / hired place, along with the basic tools and equipment (even used second hand ones are enough) are what they will need. Hence, lower cost, along with suitable differentiation makes this profession an attractive one. 
We conducted in-depth qualitative interviews with four private garage mechanics and 10 car owners in Hosur (India), who bought their cars in last one year.

\section{Advantages of Private Garage Mechanics}

The car owners see lots of value in these private garage mechanics. The following are the advantages and benefits, as perceived by the car owners, about the utility of Private Garage Mechanics.

- Location: Most of these private garages are located nearer to commercial and residential hubs, as against the manufacturer authorised service centre, which occupy a large space, which is normally not available in city centres. It is very convenient for the customers to go the private garages as per their convenient time and get their vehicles serviced.

- Pick-up and Drop facility: Since they are located nearby and cater to customers in that locality, they also offer to pick-up the vehicle from customers' place and drop them back after servicing. This facility is highly sought after by working professionals, for whom time is at a premium.

- Personal attention: Since these mechanics are well known in the locality, they pay personal attention to customers and their vehicles. Customers trust them. "Smaller facilities allow for direct communication with your mechanic. You are able to get to know your mechanic (among others) by name. He may become very familiar with your vehicle and anticipate issues or problems down the road (Neil G Chrico accessed on $20^{\text {th }}$ Aug'12 from http://edmunds.com/car-care/corner-garage-vs-dealer-service-department.html)". Such personal attention is not possible in a professional set up of a manufacturer authorised service centres, where everything works as per the laid down systems and processes. These systems and processes are always not necessarily to the benefit of the customers.

- Speed in service: These private garage mechanics complete the servicing quicker than big service centres. As these mechanics look for higher productivity and also don't go strictly by timings, they stretch extra time and finish the work as quickly as possible. Speed is the essence.

- Cost-effective : Being in unorganised sector, they servicing fee is lower. The cost structure is very lean and hence, they can afford to charge lower fee to the car owners. Those car owners, who are price sensitive and look for value for money, would always prefer these private garage mechanics.

\section{Disadvantages of Private Garage Mechanics}

- Lack of formal education: Since these mechanics are not formally qualified, their job knowledge is uncertain. One has to rely only on hands- on experience, which can be unreliable and uncertain. These private garage mechanics don't read and hence, they don't learn the theoretical aspect of new technologies.

- Possibility of non-genuine spare parts: "Small repair shops can offer OE or aftermarket parts, which are meant to substitute for the OE part. The advantage of aftermarket parts is that, like generic prescription drugs, they are supposed to perform the same function for a lot less money. There are times, though, when aftermarket parts are inferior to OE parts" (Neil G Chrico accessed on $20^{\text {th }}$ Aug'12 from http://edmunds.com/car-care/corner-garage-vs-dealer-service-department.html) In order to make more money, they tend to use such non genuine parts which have shorter lifespan, affecting the performance of the vehicle. Due to this, the car owner ends up paying more than necessary effectively.

- Warranty rejections: Many manufacturers do not extend warranty on those vehicles, which were serviced by the private garage mechanics. This is done on the assumption that the private garage mechanics don't know the job and hence, would do wrong diagnosis. Hence, if the garage mechanics do any work on the vehicle during the warrant period, the vehicle stands the risk of losing the warranty benefits.

In spite of the above advantages and disadvantages of the private garage mechanics, the potential car customers seek the recommendation of these mechanics for specific reasons, as mentioned in Figure 1, before they make the purchase decision. The key reasons for consulting the private garage mechanics are maintenance (cost and frequency), serviceability (ease of service and frequency), parts price, parts availability and fuel consumption. 


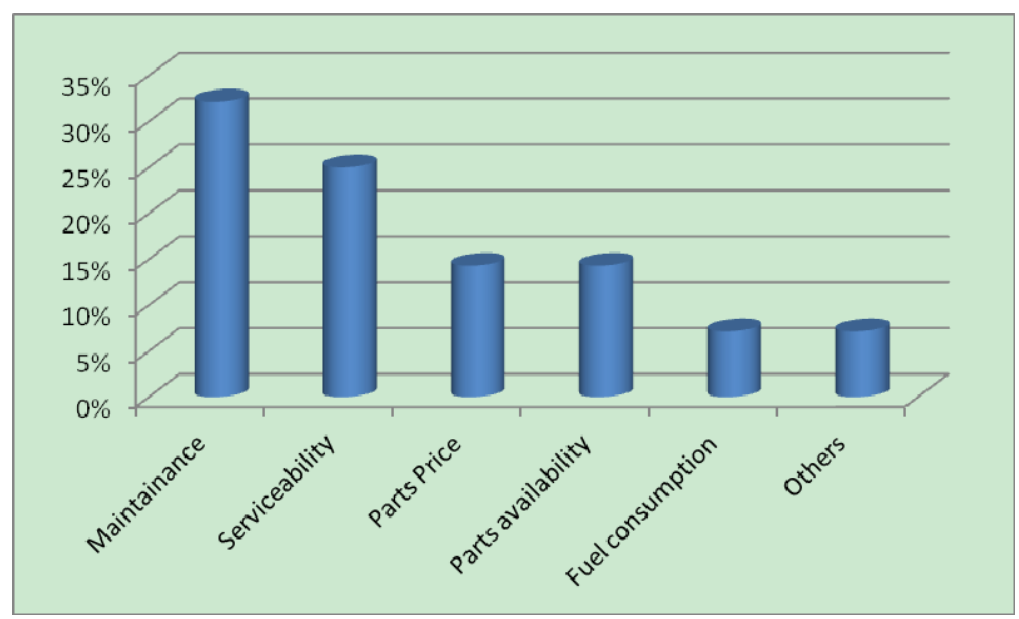

Figure 1.

On the basis of detailed qualitative interviews, the following hypotheses were formed.

Hypothesis 1 - Private Garage Mechanics are highly knowledgeable

Hypothesis 2 - PGMs' recommendations are authentic and credible

Hypothesis 3 - Potential customers seek PGMs views, before deciding on any purchase

These Hypotheses were tested thro' a questionnaire done on 50 car owners, who were from Hosur and were chosen by convenient random sampling method. They all had bought their cars within the last two years.

\section{Hypothesis 1 - Private Garage Mechanics are highly knowledgeable}

It is interesting to note that out of 50 respondents, only $8 \%$ of the respondents stated that the private garage mechanics were highly knowledgeable. In this case, the knowledge was interpreted as technical expertise. What is noteworthy to mention here is that $30 \%$ of the respondents felt that the private garage mechanics are not knowledgeable at all (Figure 2)

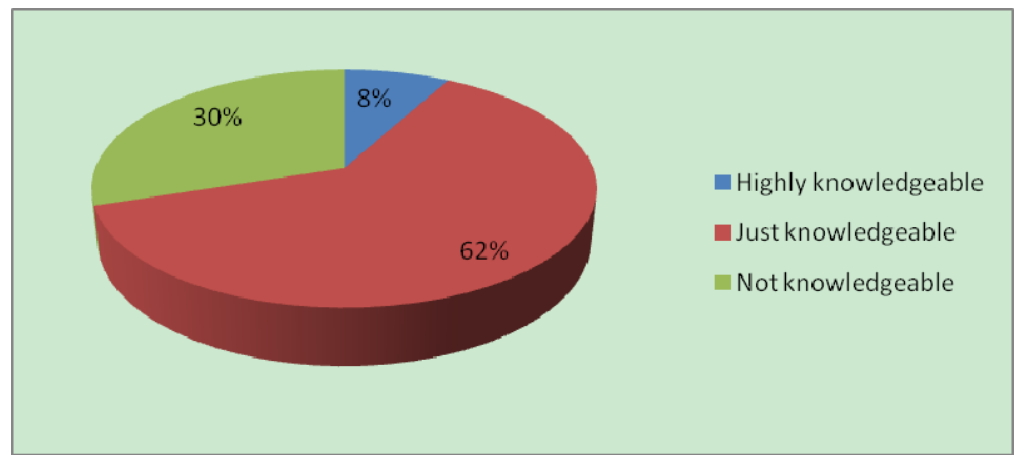

Figure 2.

The possible inference is that $70 \%$ of the respondents feel that the private garage mechanics are either highly knowledgeable or just knowledgeable. "When consumers have little or no experience with a brand or even with a general type of product or service, the resultant uncertainty will make them especially receptive to influence (Vladas Griskevicius, Robers B Claldini and Noah J.Goldstein, Applying and Resisting peer influence, MIT Sloan Management Review, Vol 49, No.2, 2008)" This means that, for these $70 \%$ of the respondents, the private garage mechanics are perceived to be having adequate technical expertise for doing the job.

However, in the last few years, all international car manufacturers have launched their latest models of cars in India. Some of the cars like Hyundai EON have been launched first in India, before launching in other countries. India has taken the lead in introducing latest automobile technology, both in terms of performance, fuel efficiency and comfort. Research and Development efforts are underway to further enhance the value of cars in 
all parameters.

Such efforts lead to new technologies being introduced. These new technologies need new methods of maintaining and repairing. For example, maintaining and repairing an electronic fuel injection pump needs highly equipped fixtures, which are costly. Apart from the fact that these mechanics have to learn these new technologies separately, the investment needed to put up these facilities is prohibitive and high. "One of the dangers of going to a smaller garage is that diagnosis is a guess and check situation, meaning that you may end up paying to replace perfectly good parts or mechanics may miss the problem entirely (Zech Browman and Brian Alexander, $\quad$ accessed on $20^{\text {th }}$ Aug'12 from http://www.driverside.com/auto-library/when_to_use_the_dealership_versus_the_independent_repair_shop)",

Such restrictions obviously put the private garage mechanics into disadvantage and their knowledge on such technologies is questionable.

The other possible inference could be that though the private garage mechanics are adequately knowledgeable on regular work needed in a car, they are not adequately skilled enough to handle more complex diagnosis of the latest cars, which come with latest technology and need highly sophisticated tools and fixtures. Lack of education also restricts their ability to acquire the new knowledge and skill.

\section{Hypothesis 2 - PGMs' recommendations are authentic and credible}

'A mechanic should possess the same qualities that you expect from your doctor and dentist; namely trust and reliability (Paul Anderson accessed from http://autos.aol.com/ article/mechanic-advice.) Many a time, the customers seek the opinion of the private garage mechanics about the performance and drive quality of brands under consideration. They do this in the belief that the private garage mechanics, being experts, will provide authentic and credible recommendation on various brands. This is truer for those customers, who are not well-versed with technical features of various cars and their comparison. These customers are unable to decide on what they want to buy, due to this lack of knowledge. In most cases, these customers seek opinion from friends, relatives and private garage mechanics. However, friends and relatives can at best give opinion on the basis of perceptions only. Their opinions are not backed up by technical information. It is in this background that the private garage mechanics play a major role in recommendations. As these mechanics seem to have necessary and sufficient expertise, their views are given higher weightage.

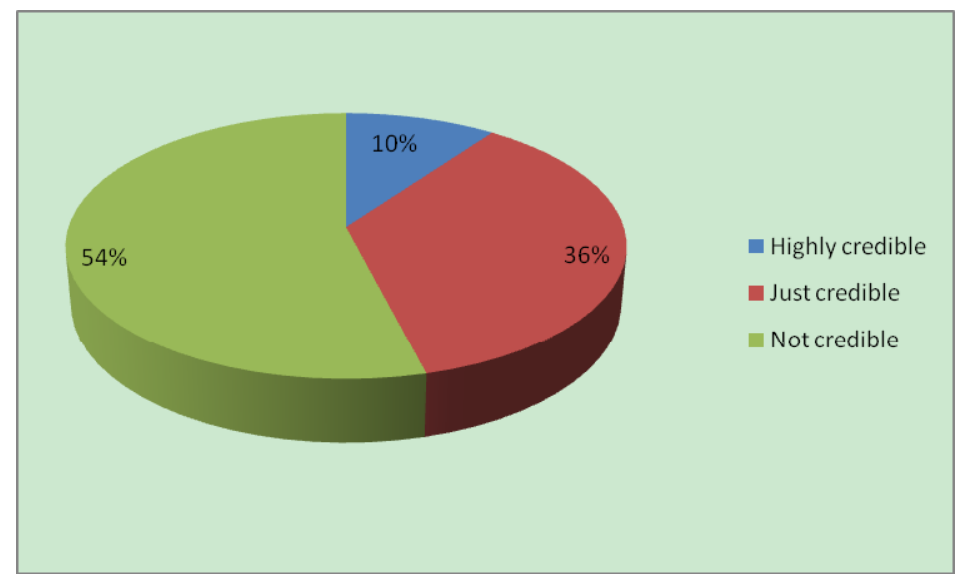

Figure 3.

However, as Figure 3 shows, 54\% of the respondents are categorical in stating that the recommendations of private garage mechanics are not credible enough to follow. Moreover, only $10 \%$ of the respondents feel that these mechanics are credible and worth considering.

The possible reasons for this problem are that the private garage mechanics and car manufacturers try to exploit the vulnerability of the potential car owners, who are technically not sound. The car makers reach out to these mechanics by various activities. Some of the activities are conducting regular mechanic meets, providing special tools free of cost or at subsidised price, etc., apart from authorising them to service their brand of cars. These aggressive car manufacturers offer incentives to the private garage mechanics, for recommending their brands to potential customers. Such activities are called 'referral scheme'. A vast majority of the private garage mechanics fall into this trap and enter into this unethical and unholy alliance. For the sake of incentives, they start 
recommending those brands, even if the brands don't match up with customers' needs and expectations. Subsequently, the potential customers get wrong recommendation. Moreover, there is a strong possibility of the private garage mechanics decrying those brands, which are technologically superior, simply because they don't understand the new technology. Hence, the recommendations of the private garage mechanics need not be always authentic and reliable.

\section{Hypothesis 3 - Potential customers seek PGMs views, before deciding on any purchase}

"Word-of-mouth communication carries particular weight as an information source because it is perceived as unbiased. Word of mouth tends to be very important in services that are difficult to evaluate before purchase and before direct experience of them (V.A. Zeithaml, L.L. Berry and A.Parasuraman, The nature and determinants of customer expectations of service', Journal of the academy of Marketing Science 21, no. 1 (1993), pp. 1-12." A decade back, if a potential customer had to purchase a car, he had to visit any of the car showrooms to get any information. Any car showroom would obviously talk positive about their brands only. One would not get any authentic information from such places. Only other option to get varied information was to talk to friends and relatives. However, the quality of technical information could be better obtained from the private garage mechanics, who were perceived to be unbiased experts. The potential customers highly valued the recommendations of these mechanics, in the absence of any other source of information.

During the study, it was observed that only $34 \%$ of the respondents consulted the private garage mechanics. Among these respondents, $24 \%$ of them were satisfied with the quality of recommendation given by the mechanics. What is more interesting is that out of $24 \%$ of the satisfied respondents, only $10 \%$ followed the recommendation to the logical conclusion ie., they bought the car model recommended by the mechanics. This only proves that even amongst those who trusted the recommendations of the mechanics, less than half of them follow the recommendations.

The times have changed now. In the digital world, all required information is available in the internet. Any information, for and against any brand, is freely available and anyone can access them. "The internet is the preferred information source among vehicle buyers. In fact $71 \%$ of both new \& used vehicle buyers said they used the internet, during the car shopping process (The "Automotive Buyer Study: Sources That Influence Purchase" by AutoTrader.com with R.L. Polk \& Co.)" There is no need for any recommendation from the private garage mechanics. In fact, the varied information available in the internet is much more credible than that of private garage mechanics. Moreover, today's customers are aware of their rights and responsibilities. They demand right things from the manufacturers and the car makers have no option but to oblige. Hence, less and less of potential customers today seek recommendation from the private garage mechanics.

\section{Managerial Implications}

The private garage mechanics do have a very important role to play in building a very positive word of mouth. On the contrary, they also can become a spoilsport, by generating negative word of mouth about a particular brand. This depends on how they are treated by the manufacturers. For the manufacturers, who spend millions in building the brand, this could be a real negative effect, if at the ground level, the private garage mechanics talk negative about the brand. Potential car owners tend not to take the risk of buying a specific brand, if the private garage mechanic gives a negative recommendation. This is understandable, as a car purchase is a life time purchase for many of the middle income families and they wouldn't take the risk of buying something against the recommendation of the private garage mechanics.

In order to avoid this, it is important for the manufacturers, who are also the brand owners, to engage these private garage mechanics positively and keep them in their good books. There are various ways of engaging them. Some of them are as given below.

1) Provide them training - This will be beneficial for manufacturers as the mechanics would do the right job on their car brand, leading to better customer satisfaction in the long run.

2) Motivate them by taking them on a guided tour to the factory - This helps in building positive perception about the manufacturer and also helps to overwhelm the mechanics with the bigness of the manufacturer.

3) Conduct meetings with them, and take their inputs on product performance - This helps boost the private garage mechanics' ego. Also, it is also possible that they are able to provide excellent insights on the vehicle performance, due to their experience.

4) Provide them with special name boards and certificates - This helps in building the association between manufacturer and mechanics, stronger, apart from informing the potential car buyers to avail the facility at more places of his choice. 


\section{Limitations of This Study}

This study is a first-hand attempt to understand the relationship between referrals and sales, from the point of view of potential customers and private garage mechanics. The study is limited to a small geographical location (Hosur, India) and the sample size is also limited. Hence, the findings cannot be generalised. A follow-up study will be needed to empirically prove the relationship between recommendation and car buying.

\section{References}

AutoTrader. (2011). 2011 Automotive Buyer Influence Study: Sources that Influence Purchase. Retrieved from http://www.weworkforyou.com/files/insights/pdf/PolkBrochureFINAL03-17-2011.pdf

Chrico, N. G. (2009). Corner Garage vs. Dealer Service Department. Retrieved from http://edmunds.com/car-care/corner-garage-vs-dealer-service-department.html

Griskevicius, V., Claldini, R. B., \& Goldstein, N. J. (2008). Applying (and Resisting) peer influence. MIT Sloan Management Review, 49(2).

Nath, C. K. (2009, April). Customers' expectations towards car in an unorganized environment- A factoral analysis. African Journal of Business Management, 2(4), 160-167.

Odekerken-Schröder, G., Ouwersloot, H., Lemmink, J., \& Semeijn, J. (n. d.). Consumers' trade-off between relationship, service package and price: An empirical study in the car industry. Emerald Article.

WiseGEEK. (n. d.). What is a car garage. Retrieved from http://www.wisegeek.com/what-is-a-car-garage.htm

Zeithaml, V. A., Berry, L. L., \& Parasuraman, A. (1993). The nature and determinants of customer expectations of service. Journal of theAcademy of Marketing Science, 21(1), 1-12. http://dx.doi.org/10.1177/0092070393211001

\section{Copyrights}

Copyright for this article is retained by the author(s), with first publication rights granted to the journal.

This is an open-access article distributed under the terms and conditions of the Creative Commons Attribution license (http://creativecommons.org/licenses/by/3.0/). 